\title{
Ojo por ojo, gato por liebre: Justicia, sustitución y regulación de la conducta sexual en Measure for Measure y El mejor alcalde, el rey
}

Ana Elena González Treviño

Facultad de Filosofía y Letras, UNAM

Mujeres acosadas por hombres en el poder y otros atavismos de género y clase; abusos, mentiras, desacatos; la dinámica del crimen y el castigo, los repliegues de la ley y la moral, son los temas que tienen en común Measure for Measure (1604) y El mejor alcalde, el rey (c. 1620) en el contexto dramático de la modernidad temprana. Existe en ambas obras una denuncia del vacío que hay entre la práctica de la virtud y el ejercicio del poder, vacío que por naturaleza se resiste a la nomenclatura y a la legislación, y que pone en evidencia la torpeza humana para hacer justicia. En la obra de Shakespeare se descubre un abismo entre la pretensión de integridad moral y la virtud verdadera; en la de Lope de Vega se observa una tensión entre la nobleza basada exclusivamente en el linaje y la nobleza basada en la virtud. La ley, a través de la figura de autoridad, opera en ambos casos para dilucidar dónde comienzan los méritos y dónde los crímenes. Y si bien en El mejor alcalde se halla una respuesta contundente en favor de la virtud, en Measure for Measure se pone en tela de juicio a la virtud misma al revelarla como discurso falsificable.

La ley traza los caminos de la justicia, caminos que, sin embargo, adolecen de zonas turbias, refugio de criminales. Cuando los caminos previstos fallan de cara al cinismo de los transgresores, la autoridad absoluta del monarca y la estratagema de la sustitución, como intercambio secreto de identidades, buscan abrir un espacio para la manipulación de valores simbólicos como último recurso para restablecer el orden. El empleo de sustitutos materiales (cartas, cuerpos, disfraces) en escenificaciones orquestadas por el gobernante representa un método de retribución sinuoso o indirecto pero legítimo, que tiene una esencia dramática incuestionable pero que también se basa en los modelos de gobierno vigentes en el periodo. 
A continuación hago un esbozo comparativo de dos obras que tratan problemáticas afines en las que se posibilita la escurridiza regulación de la conducta sexual por estos medios.

Empecemos por Shakespeare. En una Viena mítica, el duque Vicentio nombra sustituto temporal a Angelo, hombre con reputación de gran rectitud. Angelo condena a muerte al joven Claudio por haber dejado encinta a su prometida. Claudio pide la intercesión de su hermana, Isabella, que es monja. Ella acepta, pero Angelo, preso de una insólita lascivia, decide que perdonará la vida de Claudio sólo a cambio del favor sexual de Isabella. El duque secretamente organiza que Mariana, mujer abandonada tiempo atrás por Angelo, sustituya a Isabella en el lecho, amparada por la oscuridad y el silencio. Al final, el duque perdona a todos y la obra concluye con una boda múltiple.

La relación entre género y estructuras de poder determina las dinámicas sociales en Measure for Measure. El problema de fondo yace en la fractura que hay entre apariencia y realidad. En Angelo e Isabella se destaca la cualidad performativa de la virtud, pues en ella se basa la reputación de cada uno, pero hay sutilezas que revelan la miopía o incluso la ceguera de los juicios basados en las apariencias, y que escapan a la justicia.

Antes de aceptar el cargo, Angelo vacila, pregunta si no sería más acertado antes probar si tiene madera (o metal) de gobernante: 'Let there be some more test made of my metal,/Before so noble and so great a figure/ Be stamped upon $\mathrm{it}^{\prime}$ (1.1:48-50). ${ }^{1} \mathrm{El}$ duque ha pretextado un viaje con la esperanza de que su sustituto sea capaz de ponerle fin a la vida licenciosa de la ciudad, que ha crecido en desmesura; está decidido y descarta las dudas de su elegido. Aunque el duque no vacila, su elección habrá sido equivocada. Si se trata de un error involuntario o de una estrategia calculada es cuestión de interpretación, pero las implicaciones en uno u otro sentido serán importantes. El viejo consejero Escalus, cuyo nombre evoca la balanza de la justicia (scales), ha confirmado la decisión del duque. Ciego Escalus, ciega la justicia.

${ }^{1}$ William Shakespeare, Measure for Measure, ed. Katherine Eisaman Maus, The Norton Shakespeare. Based on the Oxford Edition, ed. Stephen Greenblatt et al. (Norton: New York and London, 1997). Todas las citas de esta obra serán tomadas de esta edición. En lo sucesivo sólo se indicará entre paréntesis el número de acto, escena y versos. 
Angelo conoce bien el discurso y los ademanes de la integridad, y se ha forjado una reputación de rectitud rayana en el exceso. El gracioso Lucio dice que por sus venas corre nieve en vez de sangre, y que jamás ha sentido los impulsos de la carne. (1.4:56-60) Tuvo que haber nacido del huevo de una sirena, especula, o bien fue engendrado por un par de pescados secos, desangrados; lo cierto, asegura, es que orina hielo. (3.1: 349-355) Angelo, quien se convertirá en el juez de la reproducción humana, se retrata como el fruto de una reproducción inhumana. Este modo de ser tan apasionadamente frío es un primer indicio de desequilibrio, pues el hecho de que no permita aflorar su lado humano no significa que no lo tenga, sino que lo tiene peligrosamente reprimido. Vive una grave tensión entre apariencia y realidad que lo lleva a cometer una serie de errores, atribuibles acaso a su inexperiencia en el gobierno, pero que revelarán sus muchos vicios.

Primero comete un error público de proporción. Por un lado, ordena la clausura de los burdeles, acción acorde con la encomienda de Vicentio, pero también sentencia a un castigo ejemplar a un delincuente muy menor en comparación: el crimen de Claudio es haber dejado encinta a su prometida antes del matrimonio. Su segundo error se da en la esfera privada y es más grave, pues se encapricha con Isabella, hermana y abogada de Claudio, a quien extorsiona al pedirle un favor sexual a cambio de la vida de su hermano. Es también traicionero por ordenar la decapitación de Claudio aun cuando Isabella aparentemente haya accedido a su petición, y es cobarde puesto que teme que el hermano de la ultrajada, de sobrevivir, denuncie su propia lascivia. En el simétrico diseño shakesperiano, el castigador de la incontinencia sexual resulta ser un incontinente sexual él mismo, y quien no controla su propio cuerpo, no puede controlar el cuerpo del estado. Intoxicado por su nueva posición, se olvida por completo de quién es, qué se supone que debe hacer y por qué le fue asignada tan grande responsabilidad. Su lado angelical queda reducido a una fachada endeble que deja ver un lado bestial mucho más activo e incluso siniestro. Es un ángel caído.

De hecho, hay en Measure for Measure varias reminiscencias del relato de la caída de Adán. Dios autoriza a Satanás para tentar al hombre: 
Vicentio permite que Angelo gobierne aun conociendo sus debilidades. Angelo también es Adán, favorito de Dios, y es tentado por Isabella, una Eva no sólo inocente sino también devota y aun cercana al martirio y a la santidad. El fruto prohibido que hace caer a Angelo es, paradójica y divertidamente, la espiritualidad excelsa de la novicia. Para un mojigato como él, la mujer más espiritual es la que más azuza su deseo carnal. Se dice a sí mismo: 'O what art thou, Angelo?/ Dost thou desire her foully for those things/That make her good?' (2.2:177-179) El deseo soez o perverso de la virtud es fruto de una inversión de valores que él mismo percibe como tal, pero que es incapaz de controlar.

En la llamada modernidad temprana y como parte del proyecto tanto de la Reforma protestante como de la Contrarreforma, existía un discurso socio-religioso encaminado a la regulación de la propia conducta la autarquía, el gobierno de uno mismo. Hacia fines del siglo XVI y principios del XVII se publicó un caudal de libros de filosofía moral que explican cómo ser virtuoso y ensalzan la virtud como el ingrediente básico para la convivencia armoniosa. Y si bien la máxima aspiración humana en términos morales era la autarquía, en consecuencia, uno de los peores vicios era la falta de control o incontinencia (incontinency). ${ }^{2}$ El término se aplica tanto a las funciones fisiológicas como a los apetitos de todo tipo y a las conductas instintivas en general (Ball, 1657: 330). Todas las secreciones corporales quedan por supuesto incluidas, como también todo tipo de intercambio, desde el sexual hasta el verbal (Masten, 1997: 357-82).

Si de las personas comunes se esperaba un cierto grado de mesura, de los gobernantes se esperaba en grado superlativo. Erasmo de Rótterdam publicó Institutio principis christiani (La educación del príncipe cristiano) en 1516, tres años después de El príncipe de Maquiavelo, y lo dedicó al futuro emperador Carlos V. Maquiavelo había promovido una figura de autoridad que mantuviera el control por la fuerza y la astucia, induciendo temor y castigando desacatos, aunque tuviera que incurrir en conductas inmorales. El libro de Erasmo, en cambio, insiste en la necesidad de la conducta virtuosa del príncipe para lograr un buen gobierno (Jardine, vi, vii). Su idea

\footnotetext{
2 En Measure for Measure, la palabra 'continency' se utiliza solamente una vez. Lucio la emplea con connotación sexual para referirse al rigor excesivo de Angelo: 'this ungenitur'd agent will unpeople the province with continency' (3.1.407).
} 
fundamental es que el príncipe 'reina para servir al pueblo, no para servirse de él' (Bataillon, 1996: 390). Para prepararse, el príncipe debe tener maestros ejemplares que lo sepan encaminar en la virtud hacia la autarquía. Aconseja:

Entrénate de modo que no te agrade nada que no esté permitido y recuerda que lo que es aceptable en el ciudadano particular no necesariamente lo es en ti. Lo que es un simple error en el pueblo es un crimen en el príncipe.

Entre más te permitan los demás, menos te debes permitir a ti mismo, y entre más licencia te den, más estricto debes ser contigo mismo. Aun cuando todos te aplaudan, tú debes ser tu crítico más severo.

[...] Así como no hay honores ni gratitud suficiente para honrar a un buen príncipe, así ninguna pena basta para castigar al malo.

La corrupción de un príncipe perverso se contagia más rápido que cualquier peste. Así, no hay método más eficiente para elevar la moral pública que con el modelo de un príncipe intachable. (De Rotterdam, 1997: 21$)^{3}$

Siguiendo la preceptiva erasmiana, el duque podría haber partido de la premisa de que la manera más rápida de mejorar la conducta de su degenerado pueblo era a través de un gobernante íntegro. Lo que esto dice sobre su propia persona no interesa en este momento más allá de su negación de los defectos de Angelo, cuyos errores como gobernante se ven magnificados y convertidos en crímenes. Según el modelo erasmiano, como la autoridad del príncipe sobre su pueblo es proporcional al predominio de la mente sobre el cuerpo, la autoridad de Angelo aparenta fortaleza, pero resulta frágil. Más adelante, Erasmo sostiene que 'si existe malignidad en la mente, ésta se deriva del contacto con el cuerpo, que está a merced de las emociones'. (De Rotterdam, 1997: 39). En este sentido, la incontinencia de Angelo, tanto física como emocional, tarde o temprano conduciría al caos del cuerpo político.

De hecho, Measure for Measure plantea un modelo en el que se ponen a prueba estas ideas. La ausencia del duque puede leerse como un juego, un recurso de la trama que no sólo justifica el error político de designar

\footnotetext{
${ }^{3}$ Las citas están tomadas de la edición de Lisa Jardine. La traducción es mía.
} 
sustituto a Angelo, sino que concretiza el siguiente planteamiento hipotético: ¿qué pasaría si el poder más alto, el poder de otorgar vida o muerte (mortality and mercy) (1.1:44), quedara en manos de un gobernante inepto? Si seguimos la línea interpretativa que asocia incontinencia con infantilismo, entonces Angelo no es más que un párvulo en cuanto a ética se refiere; el duque no debió dejarlo gobernar, y mucho menos esperar que purgara la ciudad de sus vicios. Ciertamente, Angelo no es un ejemplo de la conducta intachable descrita por Erasmo. ${ }^{4} \mathrm{El}$ mensaje insistente que se deriva del caso es que una fachada angelical no garantiza por mucho una regencia correcta.

El experimento del encumbrado inesperado no es nuevo. Tenemos los célebres ejemplos de Sancho Panza gobernando su ínsula y Segismundo, el príncipe encerrado, dudoso de su verdadero rango. Mas la enseñanza aquí no es sobre la bondad inherente al hombre común, como en el caso de Sancho Panza, ni sobre la naturaleza ilusoria de la realidad, como en La vida es sueño. La lección en Measure for Measure es eminentemente moral: aquel que no se gobierna a sí mismo es incapaz de gobernar un pueblo; como carece de la virtud que cimienta la fuerza de voluntad, se deja gobernar por sus pasiones y se comporta con la incontinencia de un niño. El nivel de madurez ética de Angelo nos habla de su incapacidad para gobernar, lo cual contrasta con su supuesta rectitud y nos conduce otra vez a la moraleja de que la mojigatería seduce: sedujo al duque en la persona de Angelo, sedujo a Angelo en la persona de Isabella, sedujo a Isabella en la persona del fraile/duque. Y como la verdadera tentación que es, hay que protegerse de ella.

La única prueba que necesitaba el duque para saber que Angelo no era de fiar -el abandono de Mariana-la conocía desde antes, lo cual hace que el error del duque sea el más imperdonable, aunque esta lectura, claro, va contra la intención lúdica y experimental de la obra. Más aún, Vicentio en realidad logra su objetivo, pues el despliegue público de justicia del último acto fortalece su gobierno de manera contundente y memorable. Stephen Greenblatt ha argumentado que, históricamente hablando, el perdón real era tan espectacular, que para quienes lo atestiguaban era una ocasión teatral

\footnotetext{
${ }^{4}$ Pudiera incluso leerse aquí una crítica de Shakespeare a la corriente puritana que ya desde principios del siglo XVII buscaba participar activamente en la política, y que de hecho llegaría al poder con Cromwell, pero eso rebasa la intención de este ensayo. (Maus, 2023)
} 
montada a la manera de escenas como la última de Measure for Measure (Greenblatt 1988, 10, 133-135). Varios críticos, incluyendo a Greenblatt, han observado también la proximidad entre la figura del duque y la del mismo Shakespeare, en modo similar al que se le identifica con Próspero en The Tempest. A la manera de un demiurgo, el duque oculta y revela información a conveniencia, incluyendo información relativa a su propia identidad, para manipular a los personajes de principio a fin (Greenblatt, 1992: 92| 1988: 138). Aunque su idea de gobierno pudiera parecer erasmiana en un primer momento -pues ha colocado en su lugar a un hombre 'intachable' como modelo de rectitud-a la luz de sus estratagemas resulta más bien un gobernante maquiavélico.

Measure for Measure fue estrenada en 1604 en un momento de transición en la carrera de Shakespeare. Es la última de una serie de comedias que exploran el tema de la conducta sexual, el matrimonio y la identidad personal. La trama está tomada de una obra de George Whetstone titulada The right excellent and famous Historye of Promos and Cassandra: Divided into Commical Discourses (1578), que cuatro años más tarde se publicó en forma de cuento en An Heptameron of Civill Discourses. Whetstone, a su vez, tomó la historia del italiano Giraldi Cinthio, que en 1565 publicó su propia colección de cuentos titulada Hecatommithi. No se sabe a ciencia cierta si Shakespeare leyó o no la versión de Cinthio, pero es un hecho que conocía el Heptameron de Whetstone (Harding, 1954: 126-128). Debido a fallas en el tono y la trama, Measure for Measure ha sido catalogada como una de las obras 'problemáticas' de Shakespeare. ${ }^{5}$ Suele decirse que esto se debe a la complejidad del tema y no a la habilidad del dramaturgo (Maus, 1997: 2021). Sea como fuere, no cabe duda de que se trata de una obra insatisfactoria en la que no se resuelve el planteamiento principal presentado desde el título: el problema del tanto por el cuánto. ${ }^{6}$

\footnotetext{
${ }^{5}$ El término 'problem plays' fue acuñado por Frederick S. Boas en Shakspere and His Predecessors (1896), p. 270. El grupo incluye All's Well that Ends Well, Measure for Measure, Troilus and Cressida y Hamlet. Esta categoría resultó muy popular entre la crítica y de hecho ayudó a revivir el interés por las tres primeras (Taylor, 244).

${ }^{6}$ Katherine E. Maus sugiere que el título está tomado del Sermón de la Montaña (Mateo 7:1-3): 'Judge not, that ye be not judged. For with what judgment ye judge, ye shall be judged, and with what measure ye mete, it shall be measured to you again.' Con la vara que midas serás medido.
} 
En un final que no por típico deja de ser perturbador, el duque sale del anonimato y casa a Claudio con Juliet, a Angelo con Mariana, y, se sugiere, a Isabella consigo mismo. El matrimonio se presenta como la moneda que salda todas las deudas masculinas hacia las mujeres agraviadas: la embarazada, la abandonada, y la (casi) ultrajada. Y sin embargo, esta triple boda es muy inapropiada y deja mal sabor sobre todo porque Angelo no recibe ningún castigo a pesar de que se ha comportado como un criminal -a sus propios ojos, a los de la ley, y ante las expectativas de lo que debe ser un gobernante. El hecho de que en realidad sus crímenes no se hayan consumado (la ejecución de Claudio, la violación de Isabella) sirve tan solo de pretexto para no enturbiar el final comédico, pero la impunidad de Angelo trabaja en contra de la eficacia dramática de la obra, y sus crímenes, aunque sólo esbozados, quedan como deudas que nunca se saldan. Ver a Isabella interceder por él no nos hace admirarla más a ella, sino que se acentúa la sensación de injusticia por causa de él. A Coleridge, la obra le parecía odiosa y repugnante: 'The pardon and marriage of Angelo not merely baffles the strong indignant claim of justice... but it is likewise degrading to the character of woman' (Taylor, 1990: 395; Stokes, 1989: 13). ${ }^{7}$

Ni siquiera el cómico Lucio de la trama secundaria, quien también ha pecado de incontinencia sexual, recibe el castigo anunciado. El duque ordena casarlo y luego ejecutarlo en la horca, más por haberlo insultado a él que por sus excesos carnales (5.1: 494-497). Mas la sed de justicia despertada por tantos desacatos y atropellos no se ve aplacada ni siquiera en este caso, puesto que Shakespeare decide no usarlo de chivo expiatorio, ya que una muerte así oscurecería las expectativas alegres del final de una comedia. El duque lo perdona finalmente, y todos quedan vivos y casados. Si el dilema principal de Isabella y Claudio había sido ¿qué vale más, la vida o la honra?, Lucio concluye en tono mordaz, vale más morir ahorcado que vivir cornudo. Según sus propios términos, su castigo es ser perdonado. Y con ese débil chiste se cierra el último acto. ${ }^{8}$

\footnotetext{
${ }^{7}$ Greenblatt especula que, por rara que parezca la boda de Isabella con el duque, habría sido más raro que al final ella regresara al convento debido a las convenciones teatrales imperantes (Greenblatt 1988, 176).

${ }^{8}$ Es inevitable recordar aquí la muerte de Bardolph en la horca (Henry $V$, 3.6). Bardolph era miembro del grupo de ladrones de Falstaff, y a pesar de esto goza en cierta medida de la amistad del entonces príncipe Hal. Participa tanto de esta simpatía dramática que reaparece en The Merry Wives of Windsor. Sin embargo, el rey Henry utiliza la ejecución de Bardolph para
} 
Pasemos al siguiente caso. El mejor alcalde, el rey es una de las obras más importantes de Lope de Vega. Se cree que fue escrita entre 1620 y 1623, en plena madurez de Lope. Sin embargo, no se publicó sino hasta 1635, en la Parte XXI de sus comedias, preparada para la imprenta por Lope mismo, pero publicada póstumamente (Lope Blanch, 2000: 125). Como se asienta en los últimos versos de la obra, la trama está tomada de la cuarta parte de la Crónica general de Alfonso X el Sabio, y se sitúa en la España medieval de Alfonso VIII. En el original se cuenta lo siguiente:

[Un] Infanzón que moraba en Galicia [...] tomó por fuerza a un labrador su heredad, e el labrador fuese a querellar al Emperador [...] E el Emperador envió su carta [...] E el Infanzón, como era poderoso, cuando vio la carta del Emperador, fue muy sañudo e comenzó de amenazar al labrador, e díjole que lo mataría, e no le quiso hacer derecho ninguno. [...] E el Emperador, después que supo todo el hecho [...] llamó hombres del lugar e fuese con ellos e paróse con ellos a la puerta del Infanzón, e mandóle llamar [...] E cuando el Infanzón esto oyó, hubo gran miedo de muerte e comenzó de huir, mas fué luego preso. [...] e como despreciara la su carta [del Emperador] [...] mandóle luego ahorcar ante su puerta, e mandó que tornase al labrador todo su heredamiento con los esquilmos. (Lope Blanch, 2000:121-122)

La principal modificación que hace Lope al relato medieval acentúa el claroscuro de la injusticia cometida por el infanzón o señor feudal por medio de la sustitución del despojo de las tierras por el rapto y la violación de una doncella. Está claro que dramáticamente funciona mejor la versión de Lope, pero esta sustitución nos revela una primera instancia de la cosificación de la mujer y su virginidad, que resulta intercambiable con una posesión material cuya pérdida atenta contra el honor masculino. La virginidad de la mujer es la metáfora directa de la tierra labrable, cuya fecundidad enaltece potencialmente al propietario. Por otra parte, es otro hombre, el gobernante, el que decide quién ara la tierra o quién desposa a la doncella.

Sancho y Elvira son dos aldeanos que quieren casarse. Sancho, por recomendación de Nuño, padre de Elvira, acude a solicitar la aprobación de

fincar su autoridad como rey. Es un verdadero castigo ejemplar pues significa que ni siquiera sus amigos se salvarán si rompen la ley. 
su señor feudal. El tirano don Tello accede en un principio, pero cuando conoce a Elvira queda prendado de ella y la rapta. ${ }^{9}$ Sancho pide justicia al rey Alfonso VII, quien le entrega una carta con órdenes terminantes para el raptor quien, no obstante, se niega a liberar a Elvira. Sancho reitera su petición al rey, quien acude disfrazado para hacer justicia. El monarcaalcalde hace que Tello se case con la ultrajada Elvira, para decapitarlo inmediatamente después y entregarle a ella la mitad de su hacienda. Elvira, ahora rica, queda libre para casarse con Sancho.

Como se podrá apreciar, el tratamiento de los temas en El mejor alcalde es muy distinto del que les da Shakespeare en su obra. Si en Measure for Measure la piedra de toque es la virtud, aquí esa misma virtud está asociada al orden social evocado por el concepto de nobleza. Se dibuja una relación simétricamente inversa entre la nobleza interior de Sancho y Elvira a pesar de su pobreza material, en contraste con la nobleza aparente (y ruindad interna) de don Tello y su posición de poder. Está también en juego la legitimidad del gobierno del señor feudal en contraposición al monarca absoluto, y el poder relativo de cada uno (Cañadas, 2002: 147-158). En La educación del príncipe cristiano, Erasmo distingue tres clases de nobleza. La primera y más elevada es la que se deriva de la virtud y las buenas acciones. La segunda es la que aporta la buena educación, y por último la tercera es la que proviene del linaje o la riqueza. Esta última es la más baja, al grado de que en ciertos casos ni siquiera es digna del nombre, a menos que se apoye en la virtud que, estrictamente hablando, es la única nobleza verdadera (De Rotterdam, 1997: 16).

En El mejor alcalde, el rey los sufridos protagonistas, Sancho y Elvira, entran en las tres categorías. Su nobleza se expresa en la delicadeza de su trato, pero también en palabras que delatan una educación humanista puesto que están llenas de alusiones clásicas y ornamentación retórica, rasgo que equivaldría al segundo tipo. Hacia el final de la obra se descubre que ambos proceden de familias nobles venidas a menos, el tercer tipo, lo cual confirma que Lope no subvierte el orden social de ninguna manera;

\footnotetext{
${ }^{9}$ La factibilidad del suceso es un vestigio del llamado derecho de pernada, al que sin embargo no se alude de manera directa en la obra. Ver Carlos Barros, "Rito y violación: el derecho de pernada en la Edad Media" Historia Social, UNED, Valencia, nº 16, primavera-verano 1993, pp. 3-17.
} 
representarlos realizando tareas serviles hace resaltar más aún su refinamiento innato. A Tello, en cambio, le correspondería sólo el tercer tipo de nobleza, una nobleza que es sólo aparente, basada en el dudoso mérito de su posición social.

En El mejor alcalde, el rey, Tello padece de la misma falta de compostura que se vio en Angelo, si bien él no tiene el pretexto de ser el sustituto del gobernante legítimo. Don Tello es el señor feudal y tiene atributos para autorizar el matrimonio de Sancho y Elvira. En un primer momento, Tello intenta convencer a Elvira por la buena con palabras halagüeñas y tropos enteramente convencionales para el cortejo amoroso, en el que él se presenta como sustituto de Sancho:

Mas cuando yo Sancho fuera

y él fuera yo, dime Elvira, ¿cómo el rigor de tu ira, tratarme tan mal pudiera? Tu crueldad ¿no considera que esto es amor? (II, 12-16) 10 $^{10}$

A lo que ella responde desde su inconmovible punto de certeza moral:

No, señor;

que amor que pierde al honor

el respeto, es vil deseo;

y siendo apetito feo

no puede llamarse amor. (II, 16-20)

Y aclara con contundencia epigramática:

Amor se funda en querer

lo que quiere quien desea;

que amor que casto no sea

ni es amor ni puede ser. (II, 21-24)

${ }^{10}$ Las citas de esta obra están tomadas de la edición de J.M. Lope Blanch (México: Porrúa, 2000) Los números indican acto, escena y número de versos. 
Elvira ha establecido una distinción tajante entre 'amor' y 'deseo'. El primero es un concepto refinado en tanto que casto y basado en un principio de autocontrol; el segundo entra en la categoría de los apetitos (Fernández). La incontinencia de Tello lo coloca en el nivel de las bestias, pero no lo vuelve ciego del todo al refinamiento ajeno. Por el contrario, conoce y reconoce en Elvira el discurso y la conducta asociados a la virtud y a la nobleza -su elocuencia ilustrada y la pudorosa resistencia que opone a sus avances - y esto aumenta su deseo. El problema es que, desde el punto de vista de Tello, dichos dones son incompatibles con el estamento bajo de Elvira; el giro dado a sus expectativas sólo logra excitarlo más.

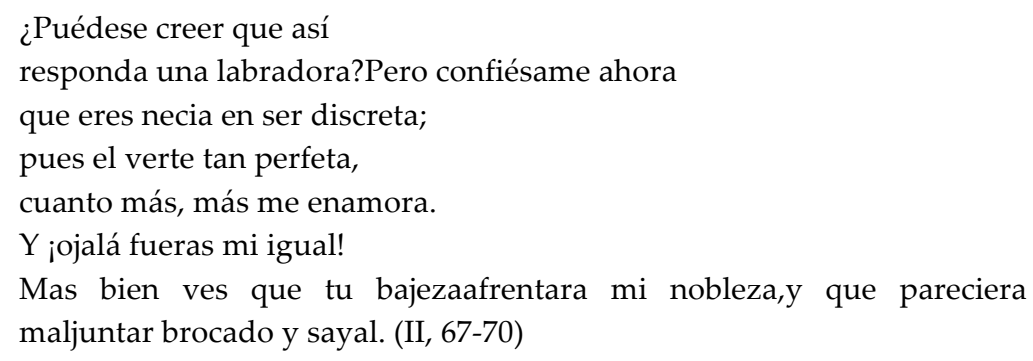

Cabe apuntar la ambigüedad del verso 'ojalá fueras mi igual', que podría leerse como 'ojalá fueras mi igual moral y no tuvieras escrúpulos', lo cual implicaría una ausencia total de pudor que la llevaría a entregársele sin reparo. Los antípodas de bajeza y nobleza, de brocado y sayal, se han invertido proporcionalmente en estos dos personajes, el noble rogando con vulgaridad, la villana resistiendo con una elegancia que a él le parece incongruente con su humilde posición social. El punto culminante que lo decide a 'forzarla' es justamente haberla escuchado 'requebrando' con Sancho. Incluso en medio de su desesperación, Elvira sabe hacer uso del ingenio y la elocuencia, virtudes que azuzan el deseo de Tello.

[...] tan airado estoy en ver que has hablado con tan noble osadía, que por fuerza has de ser mía o no he de ser yo quien fui.

[...] 
He de forzalla o matalla. (II, 249-253, 255)

A lo que su hermana, Felicia, aterrada de oírlo pronunciar estas palabras, exclama:

¿Cómo es posible libralla

de un hombre fuera de sí? (II, 256-257)

El trasfondo es una esencia humana de la que Tello se ha apartado. Un hombre fuera de sí, un hombre que se deja regir por la pasión, es un no hombre que sólo puede comportarse con bajeza. No es un hombre que se conduzca, controle o gobierne a sí mismo, sino que se deja arrastrar por sus apetitos. En esto es igual a Angelo, cuyo deseo de Isabella aumenta a la luz de la virtud moral de ésta. La discreción de Elvira despierta sentimientos encontrados en Tello, puesto que es tanto la causa del rechazo, como una cualidad que la vuelve más atractiva; por otra parte, el coqueteo discreto y culto de Elvira, su 'noble osadía' hacia Sancho, revela a Tello la disponibilidad potencial de Elvira que, por no ser hacia él, lo hace enfurecer. ${ }^{11} \mathrm{Al}$ igual que en Measure for Measure, ocurre aquí una confusión e inversión de valores que provoca la degeneración y caída del hombre obsesionado. Tello se presenta como un sustituto violento y envilecido de Sancho, el prometido legítimo y adecuado para Elvira. Felicia intercede a favor de ella refiriéndose a Sancho como 'esposo' de Elvira y éstos también se designan mutuamente como esposo y esposa, pero esto no desalienta a Tello.

Cuando se enfrentan ambos varones, se vuelve evidente la superioridad moral de Sancho, que pronuncia un discurso lleno de indignación sin faltar un punto a la deferencia debida a su señor don Tello. Está clara la dificultad de su posición, y no obstante, tiene tal dominio de la retórica de la cortesía, que logra expresar una amenaza velada que acorrala a Tello, quien a su vez sólo se escabulle con mentiras. No sólo esto: la escena demuestra que un hombre, Sancho, invadido por una pasión violenta, la ira, es capaz de dominarse a sí mismo, de ejercer la autarquía.

${ }^{11}$ En esto se parece al personaje de Juliet, que se describe más abajo. 
Elvira, como mujer, está en triple desventaja: su falta de fuerza física activa el rol de sometimiento femenino y como labradora tiene inferioridad social y de poder, pero el estereotipo de nobleza la somete al régimen de la honra. La incompatibilidad de códigos genera el sentido trágico del suceso. Su misión noble es 'guardarse', resistir, morir antes que ceder, pero su fragilidad posibilita el ser 'forzada' por Tello. Este término, 'forzada', designa una violación, mas en este contexto el cuerpo violentado de la mujer no la exime de responsabilidad y genera una culpa que se refleja en el padre. La hija se presenta como la propiedad del padre, pero también como la custodia fallida de su honra. Nuño la desconoce y la insulta incluso antes de que se haya consumado el hecho.

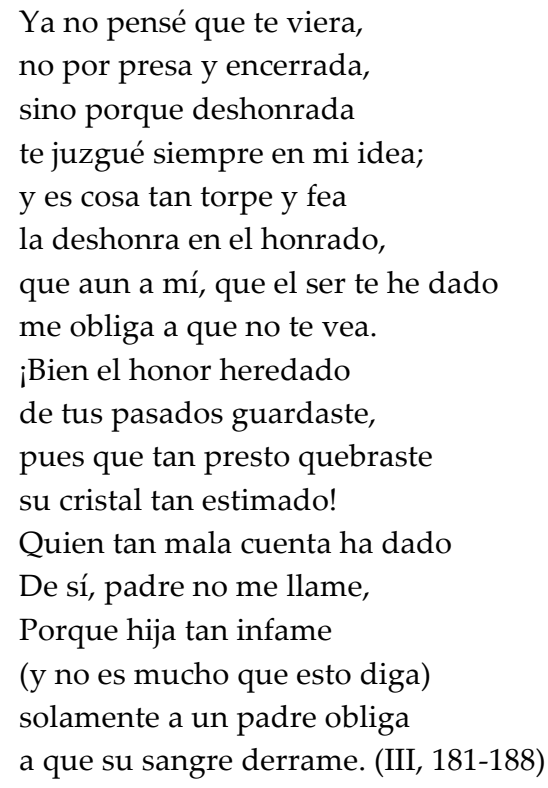

Lo curioso de El mejor alcalde, el rey es que la violación de Elvira se posterga durante un lapso de tiempo considerable. Cierto es que el postergamiento se da estando ya el cuerpo de Elvira en un cautiverio que funciona como una etapa preliminar del sometimiento, como una inmovilización previa al ultraje. Por más que se explique que Tello actúa por 
impulso, arrastrado por sus pasiones, hay una cierta negociación entre él y Elvira; la obra bien podría ser la crónica de un rapto anunciado.

Hacia el final, Elvira, a pesar de ser una simple aldeana, describe su ultraje con grandeza trágica evocadora de la misma Lucrecia.

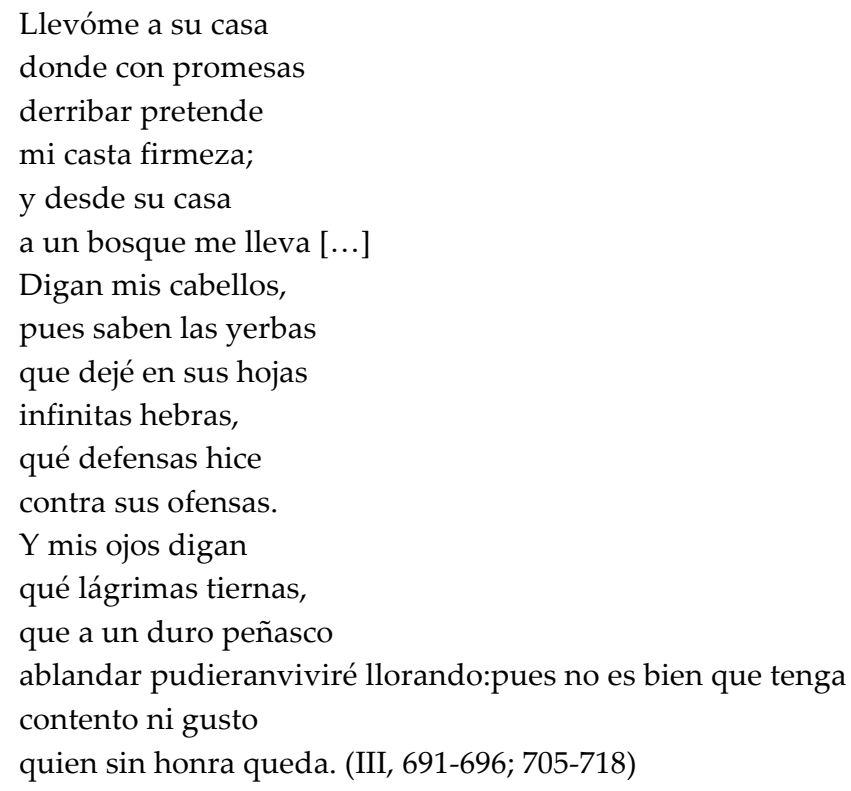

$\mathrm{Al}$ activarse el estereotipo femenino, la conducta honorable exige hacer la máxima defensa posible del honor, aun a costa de la integridad física. Esta defensa responde a un código cultural encaminado a descartar la sospecha de que haya habido consentimiento de su parte. Elvira parece relatar hechos, pero en realidad está escenificando, editando y dramatizando su resistencia para disminuir la culpa que ella misma da por sentada. Llama por testigos a sus cabellos desordenados y arrancados, y a sus ojos deshechos en llanto, pero ella misma ya ha determinado para sí un castigo de llanto eterno.

En Measure for Measure rigen los mismos valores y la misma gestualidad. Cuando el duque interroga a Juliet, la prometida de Claudio, se puede apreciar la culpa adjudicada al consentimiento femenino, que se consideraba peor incluso que el deseo masculino. 
Duke. Love you the man that wronged you?

Juliet. Yes, as I love the woman that wronged him.

Duke. So then it seems your most offenceful act

Was mutually committed?

Juliet. Mutually.

Duke. Then was your sin of heavier kind than his. (2.3:26-30)

Juliet ama a Claudio como a sí misma, y considera que ella lo deshonró tanto como él a ella, pues se refiere a sí misma como 'the woman that wronged him'. Este comentario es un revés muy poco usual de las relaciones entre los sexos, y de algún modo apunta hacia una sociedad con verdadera equidad de género. A pesar de ello, la culpa ideológica asociada al consentimiento femenino es tan tangible, que Juliet misma la acepta, al grado de que lamenta no poder morir con Claudio por el mismo pecado, pues la ley prohibía ejecutar a una mujer embarazada. ${ }^{12} \mathrm{El}$ ingenioso cinismo de Juliet para relatar su propia experiencia consensual es excepcional y proporciona un contraste muy provocador pero que no se desarrolla.

En la escena análoga de Isabella, ésta le describe al duque la gestualidad de su resistencia. Sin embargo, hay una gran diferencia con respecto a la escena de Elvira, ya que tanto la propia Isabella, como el duque mismo, como el público con quien se ha forjado un lazo de complicidad, saben que lo que dice es estrictamente falso, puesto que ella no ha estado jamás con Angelo. Isabella relata:

How I persuaded, how I prayed and kneeled,

How he refelled me, and how I replied-For this was of much lengththe vile conclusionI now begin with grief and shame to utter.He would not, but by gift of my chaste bodyTo his concupiscible intemperate lust,Release my brother; and after much debatement,My sisterly remorse confutes mine honour,And I did yield to him. But the next morn betimes,His purpose surfeiting, he sends a warrantFor my poor brother's head. (5.1; 93-103)

${ }^{12}$ Greenblatt ha explorado los efectos perturbadores del deseo femenino en Othello, en 'The Improvisation of Power', Renaissance Self-Fashioning (Chicago: University of Chicago Press, 1980), 222-254. 
El público ya ha visto a Isabella en repetidas ocasiones exaltando la honra por encima de la vida. Ahora que se supone ultrajada en lo que a final de cuentas es una escena montada y orquestada por el duque para desenmascarar a Angelo, éste dice no creerle y la manda encarcelar por calumnia. Aunque sabemos que lo que dice no ocurrió en realidad porque Isabella tuvo una doble de cuerpo en la persona de Mariana, la acción funciona en el nivel dramático para exacerbar el sentimiento de indignación e injusticia en contra de Angelo y a favor de Isabella. Tanto ella como Elvira, hacen con sus palabras la representación del ultraje con un decoro prescrito de manera formulaica incluso en sus detalles. Es digna de resaltarse la sonoridad percutiva del verso 'To his concupiscible intemperate lust', con unas esdrújulas peculiares, muy raras en el idioma inglés, y muy rara vez juntas. La violencia de sus acentos evoca la violencia del asalto sexual descrito por Isabella.

El hecho de que los argumentos tradicionales no sean persuasivos en primera instancia, se debe en parte al machismo prevalente -discurso del que también se aprovecha el duque al defender a Angelo: es más fácil que mienta una mujer haciendo aspavientos, a que falle el sustituto que él mismo eligió. Angelo mismo lo predijo:

Who will believe thee, Isabel?

My unsoil'd name, th'austereness of my life,

My vouch against you, and my place i' th' state,

Will so your accusation overweigh,

That you shall stifle in your own report

And smell of calumny. (2.4: 154-159)

Angelo aquí arguye con base en la fuerza de las apariencias que tan bien ha sabido guardar. No obstante, Shakespeare también hace notar la calidad teatral y por ende falsificable de los argumentos de Isabella. Esto supone un grave peligro para las mujeres afectadas, y plantea un problema retórico irresoluble: a mayor elocuencia, mayor sospecha, pues la persuasión es una especie de seducción.

Elvira e Isabella comparten un mismo código ético que las hace valorar la honra más que la vida. Su supervivencia en sociedad depende de 
su propio autocontrol o autarquía según sean capaces de defenderse, pero también de su habilidad para controlar a los hombres que las desean y que son incapaces de controlarse a sí mismos. Tello y Angelo tienen un arma, el poder, que no saben atemperar con la virtud. Esta arma de los hombres entronizados es burda, primitiva y eminentemente masculina. Las mujeres, en cambio, nobles en el primer sentido erasmiano, para defender su castidad cuentan exclusivamente con el arma de la elocuencia, pues su cuerpo queda descartado por débil. Lo único que pueden hacer es hablar, o mejor dicho, representar de la manera más convincente posible el papel prescrito por su sociedad y cultura, para tratar de persuadir al agresor de no actuar en su contra, o, si esto falla, de convencer a la sociedad a posteriori de que el acto se cometió en contra de su voluntad. La retórica que emplean para lograrlo es un arma fina, civilizada y femenina, de cuya eficacia depende el veredicto.

En un principio, Isabella utiliza cierta retórica para tratar de disuadir a Angelo de la ejecución de Claudio. Su discurso está construido según los principios de la retórica clásica y adornado con tropos ortodoxos. Su mera formalidad por sí sola pareciera garantizar un resultado positivo. Da inicio con un poderoso exordio que establece su carácter moral o ethos:

There is a vice that I do most abhor, And most desire should meet the blow of justice, For which I would not plead, but that I must; For which I must not plead, but that I am

At war' twixt will and will not. (2.2:,29-33)

Dicho ethos la representa como una mujer de solidez moral incuestionable: no por defender a su hermano debe entenderse que defiende la fornicación, aclara. Shakespeare se toma ciertas molestias para asentar la incorruptibilidad de Isabella. Para ingresar al convento, tuvo que jurar no hablar con hombres más que en presencia de la priora, y desde entonces debe elegir entre hablar o mostrar su rostro (1.4.10-13). La imagen física de la mujer, especialmente el rostro, es un obstáculo para la percepción de su razón, manifestada a través del habla. Resulta significativo el hecho de que Isabella tenga que salir del convento para interceder por Claudio instigada nada menos que por el reprobable Lucio, e incluso el hecho de que se presente descubierta ante Angelo. Lucio arguye: 'when maidens sue,/ Men 
give like gods; but when they weep and kneel,/All their petitions are as freely theirs/As they themselves would owe them' (2.1.80-84). Para lograr esto, empero, tiene que salir a la luz la virginidad o doncellez de la solicitante (maidenhead o maidenhood), atributo invisible y garantía de inocencia. La doncella debe esgrimir su cuerpo y sus gestos como herramienta de convencimiento, un acto de exhibición que contradice la modestia que dice profesar. El mundano Lucio, como director de escena, la instiga a eso, reprochándole varias veces su frialdad, e instándola a expresarse con más calidez. La contradicción perdura: llorar y arrodillarse son armas que sirven para persuadir, pero también apelan a las facultades más bajas del hombre y pueden resultar contraproducentes, como de hecho ocurre, pues la representación de la pureza femenina quizás convenza, pero también atiza el deseo masculino. ${ }^{13}$

Las primeras palabras de intercesión pronunciadas por Isabella tienen un tono legal muy parecido al empleado por Portia en el juicio de The Merchant of Venice, mas recordemos que Portia está vestida de hombre, y si su retórica fracasa ante Shylock, es por motivos totalmente ajenos al discurso de la sexualidad. El hecho es que existe un antagonismo explícito entre mente y cuerpo. Si la mujer se presenta como tal, debe renunciar a sus capacidades intelectuales y permanecer callada. Si quiere hablar, deberá cubrirse el rostro como las monjas o vestirse de hombre como Portia o como Rosalind en As You Like It.

Es significativo también el hecho de que cuando por fin sale a escena Mariana en el último acto, aparece cubierta por un velo. Se disculpa ante el duque, pero dice que no mostrará su rostro hasta que su marido se lo permita. ${ }^{14}$ Queda aquí claro que el rostro, como la virginidad, se considera propiedad exclusiva del marido. Sin embargo, cuando el duque la interroga, Mariana dice no ser ni doncella ni esposa ni viuda. ¿Será una prostituta?,

${ }^{13}$ En el siglo XVIII, en la época de las grandes actrices, se recuerda especialmente la interpretación que hizo Mrs. Cibber de Isabella en 1738. The London Chronicle (No. 280, Oct. 1214,1738 , p. 367) informó que 'the elegance of her figure, the musical plaintiveness of her voice, and the gentleness of her manners' sedujo tanto a Angelo como al público (Taylor, 117). Es evidente que la actriz explotó su presencia física, voz y gestos de una manera non santa.

${ }^{14}$ Es un gesto con valor ritual, sin duda, que en el contexto actual nos remite al debate en torno al velo musulmán. 
insinúa Lucio, salaz. ${ }^{15}$ No, es la prometida de Angelo, quien finalmente le pide que se quite el velo.

My husband bids me; now I will unmask.

This is that face, thou cruel Angelo,

Which once thou swor'st was worth the looking on.

This is the hand which, with a vowed contract,

Was fast belocked in thine. This is the body

That took away the match from Isabel,

And did supply thee at thy garden-house

In her imagined person. (5.1:201-208)

Es verdad, como no existe un término preciso para describir la situación legal de Mariana, acierta al decir que ella no es más que un cuerpo, la doble de cuerpo de Isabella, dispuesta a 'sacrificarse' sin repugnancia y respaldada por la ley. Mariana menciona un contrato por juramento, a vowed contract, mediante el cual su mano -es decir, su doncellez-había sido concedida a Angelo con anterioridad. Existían dos tipos de contrato matrimonial por mutuo consentimiento: un contrato expresado en tiempo futuro (sponsalia per verba de futuro) y un contrato expresado en tiempo presente (sponsalia per verba de praesenti). Ambos eran válidos y podían ir seguidos de la consumación, pero el primero se podía romper. (Harding, 113-114; López Herrera, 222-226). Tanto el compromiso de Claudio con Juliet, como el de Angelo con Mariana, pertenecen al primer tipo, que, a juzgar por el tratamiento que da el duque a Mariana, se confirma que sí permitía privilegios conyugales a los contrayentes (Maus, 2021). El compromiso de Elvira con Sancho y su tratamiento de 'esposos' sugiere la existencia de un contrato análogo. Sin embargo, Angelo y Tello pueden elegir no reconocer dicho contrato por ser informal. Se revela entonces un terreno resbaladizo en cuanto a la regulación de la sexualidad, un área que la ley procura definir y controlar, pero que no queda enteramente clara a la hora de administrar justicia.

Esto parecerá problemático sólo mientras el duque esté ausente, pues la última palabra la tiene siempre la figura de autoridad, duque o rey

${ }^{15}$ Gary Taylor ha observado que, más allá del principio, las prostitutas brillan por su ausencia en esta obra en la que la disipación sexual está bajo la lupa (Taylor, 388-395). 
absoluto; su fallo es inapelable y favorece a la mujer. Se observa, pues, un movimiento inverso entre los hombres y las mujeres de ambas obras (exceptuando la figura de autoridad masculina, por supuesto). Tello y Angelo ejercen el poder sin autarquía y se derrumban. Elvira e Isabella se resisten al ultraje tanto como pueden, y ascienden. Tanto Lope como Shakespeare promueven un orden social en el que se proteja a la mujer de la violencia masculina, y la colocan en un sitio privilegiado. En la balanza moral y judicial, la palabra y la gentileza pesan más que la brutalidad y el desacato. En la obra de Lope esto se cumple sin lugar a dudas, pero, ¿ocurre lo mismo en la de Shakespeare? No lo creo. La diferencia radica en el uso y el valor que se le da a los sustitutos.

En El mejor alcalde, el rey, las sustituciones fracasan. Debido a la distancia geográfica que hay entre el rey y Tello, su primera acción en favor de Sancho y Elvira consiste en enviar una carta ordenando la liberación de Elvira. La carta y el sello reales resultan reemplazos insuficientes de la figura real para hacer obedecer a Tello. Cuando el rey se presenta en persona disfrazado de un simple alcalde, Tello tampoco lo reconoce y está a punto de volver a desobedecer.

Rey. Pues, ¿qué diferencia tiene del Rey quien en nombre viene suyo?

Don Tello. Mucha contra mí.

Y vos, ¿adónde traéis

la vara?

Rey. En la vaina está

de donde presto saldrá,

y lo que pasa veréis.

Don Tello. ¿Vara en la vaina? ¡Oh, qué bien!

No debéis de conocerme.

Si el Rey no viene a prenderme, no hay en todo el mundo quién.

Rey. ¡Pues yo soy el Rey, villano! ...

Don Tello. (...) ¿Vos mismo? ¿Vos en persona?

Que me perdonéis os ruego.

Rey. Quitadle las armas luego.

Villano, ipor mi corona, 
que os he de hacer respetar

las cartas del Rey! (III,632-651)

Acto seguido, Elvira relata cómo la forzó Tello, y el rey de inmediato dicta su sentencia:

Pésame llegar tarde:

llegar a tiempo quisiera

que pudiera remediar

de Sancho y Nuño las quejas,

pero puedo hacer justicia

cortándole la cabeza

a Tello: venga el verdugo. (III,737-743)

Los sustitutos del rey (la carta, el disfraz) son versiones demasiado difusas de su persona que no bastan para intimidar a Tello, pero su presencia, una vez descubierta, basta para despachar el asunto con toda diligencia. La hermana de Tello intercede, pero el rey es tajante:

Cuando esta causa no hubiera,

el desprecio de mi carta,

mi firma, mi propia letra,

¿no era bastante delito? (III,746-751)

La naturaleza ambigua de la nobleza, cuyo espectro va de la nobleza heredada a la que se deriva de la virtud, se disuelve ante la claridad tonante de los decretos reales. La ley es imperfecta y por ello el derecho divino que ejerce el rey en su persona está por encima de ésta y lo autoriza para llevar a cabo un juicio sumario. Se ha dicho que Lope escribió esta obra en apoyo a la monarquía absoluta de los Habsburgo. A diferencia de otras obras como Fuenteovejuna y Peribáñez y el Comendador de Ocaña, el rey no aparece sólo al final, sino desde la mitad de la obra, por lo cual su protagonismo es mayor. No es un rex ex machina, pero corrige actitudes tiranas en el señor feudal; su palabra tiene peso suficiente para restaurar el orden (Rodríguez Medina). En realidad la propuesta es que, ante la peor vileza, la figura del rey es insustituible. 
Cabe mencionar una segunda instancia de sustitución potencial en el personaje cómico del rústico Pelayo, presunto pretendiente de Elvira, que encarna a un labrador burdo y sin educación. Funciona como contrapunto de Sancho, y si bien ambos son estereotipos -éste del villano noble, aquél del villano rústico-gracias a Pelayo, Sancho se perfila también como un personaje irremplazable.

Por otra parte, en Measure for Measure el mecanismo de sustitución triunfa y trasciende la naturaleza falible tanto de la ley como de quienes la ejercen. La primera sustitución es la del duque por Angelo, quien estará a prueba a ojos del público. Quizás el duque ha puesto delante suyo a un títere para no encarar su propia ineptitud, pero Vicentio, sin ensuciarse las manos, resurgirá con más brillo que nunca.

En segundo lugar tenemos el dilema principal de la obra. La virginidad de Isabella es intercambiable con la vida de Claudio -'a head for a maidenhead'. Para Isabella, el precio es demasiado elevado, no así para su hermano, que trata de convencerla de ceder. La sustitución de Isabella por Mariana hace posible el intercambio sin perjuicio para nadie.

En tercer lugar, el duque ha sustituido su ropa y cargo por los de un fraile anónimo que puede observar la acción sin incurrir en ninguna responsabilidad. El motivo del gobernante disfrazado se repite en El mejor alcalde, como ya se comentó; sirve para distanciar a la figura real, para crear una profundidad dramática y narrativa que acentúa la grandiosidad de su aparición cuando ésta por fin ocurre. A través del disfraz, la figura de autoridad crea su propio telón de fondo. $\mathrm{Y}$ es en calidad de fraile que el duque sugiere la sustitución de Isabella por Mariana en el lecho de Angelo; el duque como tal no no se compromete. ${ }^{16}$

El intercambio de una mujer por otra es sin duda la sustitución más importante de la obra. Angelo cree poseer a Isabella cuando en realidad ha consumado la unión con su antigua prometida. Se propone una astuta equivalencia de cuerpos para por un lado salvaguardar el honor de la heroína, y por el otro, hacer que Angelo quede socialmente obligado a casarse con Mariana. No contento con esto, el duque, en la persona del fraile,

${ }_{16}$ Este truco lo utiliza Shakespeare también en All's Well that Ends Well; a pesar de ser tan burdo, funciona dramáticamente. 
hace que Isabella finja públicamente que en realidad fue ella quien estuvo con Angelo con la intención de representar ante éste el crimen que él mismo cree haber cometido y que para él es real. Una vez más, está de fondo el tema del título, Measure for Measure: con la vara que midas serás medido.

Como en la obra se ha planteado la equivalencia entre la virginidad de la mujer y la vida del hombre ('a head for a maidenhead'), así como se representa el desfloramiento de Isabella con palabras, se impone la representación de la muerte de Claudio. El duque convence a Angelo de que se ha llevado a cabo la ejecución, presentándole la cabeza de un hombre muy parecido al hermano de Isabella. (Se nos aclara que en realidad es la de un pirata que, oportunamente, murió de fiebre en prisión.) Esta grotesca sustitución es otro de los malabarismos estratégicos que el duque se ve forzado a hacer para hacer justicia y poner en evidencia a Angelo; es por ello que mantiene vivas las dos historias, la verdadera y la ficticia, hasta la conclusión de la obra.

En repetidas ocasiones se sugiere que el juez debe ponerse siempre en el lugar del criminal. Muy al principio, Escalus insta a Angelo a la compasión, preguntándole si él mismo no habrá sentido alguna inclinación venérea alguna vez, si estaría dispuesto a condenarse a sí mismo del mismo modo. ${ }^{17}$ A lo que Angelo responde con santurronería:

'Tis one thing to be tempted, Escalus, Another thing to fall. [...]

You may not so extenuate his offence

For I have had such faults; but rather tell me, When I that censure him do so offend, Let mine own judgement pattern out my death, And nothing come in partial. Sir, he must die. $(2.1,17-18 ; 26-31)$

No vacila en ofrecerse a ser medido con la vara que mide, aun cuando él mismo advierte desde un principio que no se le había sometido en realidad a ninguna verdadera prueba. Más adelante, Escalus informa al duque de la severidad de Angelo, a lo que el duque responde: 'he hath sentenced himself' (3.1: 475), se ha sentenciado a sí mismo.

${ }^{17}$ Los temas de Measure for Measure son en general comparables con el poema de Shakespeare The Rape of Lucrece, pero este pasaje lo es de manera particular. 
El verdadero parteaguas de la obra es el momento en que el duque decide intervenir para enderezar lo torcido. Su arma principal es la sustitución que consiste en trazar equivalencias y hacer reacomodos con el menor costo social posible. Con sustituciones comenzó la obra, con sustituciones termina. El duque edita y compone la historia como un verdadero dramaturgo, reconstituyendo las relaciones entre las personas, aprovechando los vacíos y dobleces del aparato de justicia. Al igual que en El mejor alcalde, sólo él está por encima de la ley, y sólo él puede perdonar la vida de Angelo.

Una interpretación miope hablaría en favor del triunfo del amor y de la superioridad de la caridad cristiana en detrimento del rigor inhumano de la ley destemplada, o de la autoridad inapelable del monarca absoluto por encima de los atropellos del señor feudal. No obstante, a diferencia del efecto dramático de justicia que produce la decapitación final en la obra de Lope, en Measure for Measure el precio del final feliz es demasiado alto, y su armonía aparente incomoda más de lo que complace. Las cuentas no cuadran. 


\section{Referencias}

Aebischer, Pascale (2008): "Silence, Rape and Politics in Measure for Measure". En Shakespeare Bulletin, Vol. 26, No. 4, invierno. Close Readings in Theatre History.

Ball, John (1657): "The Government of the Tongue", The Power of Godliness (Londres: By Abraham Miller, for George Sawbridge)

Barros, Carlos (1993): "Rito y violación: el derecho de pernada en la Edad Media". En Historia Social, UNED, Valencia, nº 16, primaveraverano, pp. 3-17.

Bataillon, Marcel (1996): Erasmo y España. México: FCE.

Boas, Frederick S.(1896): Shakspere and His Predecessors (New York: Scribner)

Cañadas, Iván (2002): "Parable, Justice and the Disguised Ruler in Shakespeare's Measure for Measure and Lope de Vega's El mejor alcalde, el rey". En Shakespeare Yearbook Vol. 13, edición especial, publicada como Shakespeare and Spain ed. José Manuel González y Holger Klein (Lewiston, NY: Edwin Mellen), pp. 147- 158.

- (2005): Public Theater in Golden Age Madrid and Tudor-Stuart London: Class, Gender and Festive Community. Londres: Ashgate.

Fernández, Jaime (s.f.): “Tensión de valores (honor-riqueza) en La prueba de los amigos de Lope de Vega". Biblioteca Virtual Miguel de Cervantes.

Greenblatt, Stephen (1990): Learning to Curse: Essays in Early Modern Culture. Nueva York y Londres: Routledge. 
- (1988): Shakespearean Negotiations: The Circulation of Social Energy in Renaissance England. Berkeley y Los Angeles: University of California Press.

Harding, Davis (ed.) (1954): The Yale Shakespeare. Measure for Measure. New Haven: Yale University Press; Londres: Oxford University Press.

de Vega, Felix Lope (2000): Fuente Ovejuna. Peribáñez y el comendador de Ocaña. El mejor alcalde el rey. El caballero de Olmedo (J. M. Lope Blanch [biografía y presentación de las obras]). México: Porrúa.

López Herrera, Francisco (2006): Derecho de familia (Universidad Católica de San Andrés)

Masten, Jeffrey (1997): "Playwrighting: Authorship and Collaboration". En A New History of Early English Drama (John D. Cox y David Scott Kastan [eds.]) Nueva York: Columbia University Press.

Maus, Katherine Eisaman (1997): “'Introduction' to Measure for Measure". En The Norton Shakespeare. Based on the Oxford Edition (Stephen Greenblatt et al. [ed.]) Norton: Nueva York y Londres.

Rodríguez Medina, Pablo (2003): “El rey en el teatro clásico español". En La ratonera: Revista asturiana de teatro. Núms. 8 y 9 (septiembre). (http://www.laratonera.net/numero8/n8_rey2.html)

Rotterdam, Erasmo de (1997): The Education of a Christian Prince with the Panegyric for Archduke Philip of Austria (Lisa Jardine [ed.]). Cambridge: Cambridge University Press. Trans. Neil M. Cheshire, Michael J. Heath, and Lisa Jardine.

Stokes, Francis Griffin (1989): Who's Who in Shakespeare....New York: Crescent Books, 1989. 
Taylor, Gary, 1990. Reinventing Shakespeare: A Cultural History from the Restoration to the Present. Londres: The Hogarth Press. 